\section{Memoria de una invasión \\ La fotografía y la Guerra del Pacífico $(1879-1884)^{1}$}

\author{
Renzo Babilonia Fernández Baca*
}

Imágenes de guerra (1879-1881)

E n 1879, Carlos Díaz Escudero y — Eduardo Clifford Spencer, que habían conformado una sociedad, viajaron a documentar como fotógrafos la campaña militar chilena en Bolivia y el Perú.

Al iniciarse la Guerra del Pacífico la fotografía era todavía un ritual costoso y solemne, durante el cual los retratados debían permanecer inmóviles y, dependiendo de las condiciones de luz, posar algunas centésimas o incluso segundos para el lente del fotógrafo. Fue recién a partir de la Guerra Civil Española (1936-1939), con la imagen tomada por Robert Capa del miliciano republicano alcanzado por un disparo, que la fotografía de guerra llegó a captar lo que Henry Cartier Bresson llamó "el momento decisivo". 2

Por ello, las fotografías tomadas por la sociedad Díaz y Spencer podrían ser clasificadas sobre la base de una organización de las imágenes respecto a todo lo que sucedía antes y después de un hecho histórico determinado.

* El libro La fotografía durante la Guerra del Pacífico, del mismo autor, se encuentra en proceso de edición por Editorial Planeta.

1 El Tratado de Ancón fue firmado en 1883. Sin embargo, las últimas tropas de ocupación chilenas recién abandonaron el Perú en agosto de 1884.

2 El momento decisivo: el momento esencial, culminante, que resume una situación y que es el que el fotógrafo debe procurar captar. 
Pongamos como ejemplo un enfrentamiento armado. ¿A qué nos referimos? A que la fotografía no podía aún entrar al campo de batalla y documentar el drama que allí ocurría. Por lo tanto, debía limitarse a retratar a las tropas y a los principales jefes de los ejércitos en sus campamentos antes de partir al combate. Y, de la misma manera, una vez terminada la batalla, se fotografiaba a los sobrevivientes, prisioneros, muertos y ruinas de la ciudad o fortaleza que había sido vencida o saqueada.

Como ejemplo de ello, existen fotografías del Regimiento Segundo de Línea en Antofagasta, antes del inicio de la invasión al Perú, ${ }^{3}$ e imágenes de la ceremonia de entrega ${ }^{4}$ de su estandarte perdido en la batalla de Tarapacá: ${ }^{5}$ El regimiento chileno fue derrotado por las tropas peruanas el 27 de noviembre de 1879 y en aquel enfrentamiento perdió su estandarte. Posteriormente este fue recuperado en Tacna, una vez que esta ciudad cayó en poder del Ejército de Chile, ${ }^{6}$ y devuelto en una ceremonia especial presidida por el general Manuel Baquedano ${ }^{7}$ en Lurín a pocos días del ataque a la ciudad de Lima. El fotógrafo del siglo XIX solo podía documentar las matanzas una vez que estas habían concluido. De ninguna manera era capaz de acompañar, como sí lo haría a partir del siglo $\mathrm{XX}$, a los ejércitos en batalla.

Ocurre lo mismo con las fotos que se conservan del ejército chileno antes y después de las batallas por Lima. ${ }^{8}$ En las imágenes anteriores a los enfrentamientos en San Juan y Miraflores se aprecia el desembarco de las tropas invasoras para atacar la capital peruana, ${ }^{9}$ fotos de regimientos en su campamento de Lurín, ${ }^{10}$ e incluso cómo se detienen en un puente para retratarse antes de continuar su avance en dirección a las posiciones defensivas de San Juan y el Morro Solar.

Los cruentos enfrentamientos, de los que daban cuenta los diarios de la época y los testimonios de los combatientes peruanos y chilenos, no podían ser fotografiados. Las cámaras todavía eran muy grandes, los equipos muy pesados y no había posibilidad de congelar la acción. Hacia 1881 el momento decisivo de cualquier acción militar correspondía al dibujo y a la pintura.

3 Toma de Pisagua: 2 de noviembre de 1879.

49 de enero de 1881

$5 \quad 27$ de noviembre de 1879 .

$6 \quad 26$ de mayo de 1880.

7 Comandante en jefe del ejército chileno los años 1880 y 1881.

813 y 15 de enero de 1881.

921 de diciembre de 1880.

10 Fines de diciembre de 1880 hasta el 12 de enero de 1881. 
Por eso solamente pueden observarse imágenes de oficiales chilenos posando junto a muertos peruanos y material bélico capturado. El horror ha concluido y la fotografía solo registra lo que el vencedor, el que se ha quedado con el terreno al final del día, quiere mostrar. ¿Cómo se representa la victoria? Mostrando los muertos, la tecnología (cañones, trincheras y defensas) y las ciudades destruidas del enemigo: siempre retratadas y humilladas con las banderas del triunfador en sus principales edificios públicos. El vencedor, en cualquier guerra y en toda imagen que evoque una victoria, se coloca en un plano superior respecto al vencido y su uniforme se verá impecable cuando pose junto al armamento capturado o los muertos enemigos.

Otro aspecto analizable en las fotografías de Díaz y Spencer es que en cualquier imagen en la que destaque una bandera chilena la composición siempre girará en torno a ella: ya sea ubicada al centro de la imagen o en un plano superior respecto al de sus propias tropas. En esos casos aparecerán los militares chilenos en bloques, no interesando el retrato individual sino la intención de dar una idea de cohesión, de disciplina, y una apariencia de uni- dad nacional. Gonzalo Leiva ${ }^{11}$ se refiriere a las fotografías de Díaz y Spencer como:

\begin{abstract}
Una galería de imágenes que constituyen la base del paradigma masculino en el imaginario nacional en momentos que la nación chilena configura su contenido cultural. En otras palabras, vemos a la fotografía como una tradición visual moderna que le entrega contenidos eficientes a la configuración del imaginario patrio y de la identidad propiamente chilena. ${ }^{12}$
\end{abstract}

La importancia que se dio en Chile a la imagen durante la Guerra del Pacífico fue tal que entre las celebraciones oficiales decretadas por la toma de Lima se organizó una exposición fotográfica con las vistas tomadas por los agentes especiales:

\section{Programa oficial en Santiago ${ }^{13}$ \\ Santiago enero de 1881}

En celebración de las espléndidas victorias obtenidas por el ejército de Chile, i de la entrada triunfal a la ciudad de Lima, la Intendencia autorizada por el Supremo Gobierno i de acuerdo con la Comandancia Jeneral de Armas, decretó las siguientes solemnidades que tuvieran lugar el jueves 20 a las horas que se indican a continuación:

11 Curador del archivo fotográfico del Museo de Historia Nacional de Chile.

12 LEIVA QUIJADA, Gonzalo. "Representación fotográfica en la Guerra del Pacífico: Una visión chilena". Ponencia en el Congreso de la Sociedad Iberoamericana de Historia de la Fotografía, p. 120.

13 AHUMADA MORENO, Pascual. Recopilación completa de todos los documentos oficiales, correspondencias $i$ demás publicaciones referentes a la guerra. Tomo IV. Valparaíso, 1887, p. 414. 
A nosotros nos interesan las actividades del sábado 22 de enero de 1881:

\section{NUEVO PROGRAMA}

El sábado a las 8 P.M. se exhibirán desde la fotografía de los señores Díaz Spencer variadas e importantes vistas que representarán las acciones más gloriosas de la presente campaña, i a los jefes que más se hubieren distinguido en ella. ${ }^{14}$

La fotografía chilena durante la Guerra del Pacífico no necesariamente mostraba las acciones militares tal como se llevaron a cabo. Es común ver imágenes en las que los militares se asemejan a actores de una obra cinematográfica: oficiales que parecen estar visitando los lugares donde se produjeron las batallas posan junto a los volados cañones de las defensas de Arica. De la misma manera, también se puede observar una imagen en la que prisioneros peruanos son obligados a tenderse en el suelo y fingir estar muertos, encontrándose rodeados de tropas chilenas que izan una bandera, notoriamente dibujada en la fotografía, y que intenta representar la toma del Morro de Arica del 7 de junio de 1880. En estos casos el fotógrafo actúa como el director de una obra de gran envergadura. Tiene tanto poder como un general o un ministro de Guerra en campaña, y las tropas, que en algunas fotografías llegan a cientos de hombres, deben obedecer sus órdenes y no pueden moverse hasta que el retratista considere que su trabajo ha terminado.

Existen diversas opiniones sobre el trayecto que llevaron a cabo Díaz y Spencer para documentar la Guerra del Pacífico. Para el coronel chileno Pedro Hormazábal, ${ }^{15}$ concurrieron inicialmente a Valparaíso a fotografiar la llegada del buque chileno Covadonga después del combate de Iquique. ${ }^{16}$ Después documentaron la llegada del Huáscar a Valparaíso y su bautizo como nave de guerra chilena. ${ }^{17}$ Posteriormente visitaron el campamento militar chileno en Antofagasta y Caracoles, fotografiando las unidades y regimientos en dos tipos de vistas: una del cuerpo de oficiales y otra general de cada regimiento en formación de bloque de batallones con su banda de músicos a la cabeza y sus comandantes en primer plano. A partir de allí iniciaron el registro gráfico del avance chileno hasta llegar a Lima.

14 Expreso mi agradecimiento al señor Juan Carlos Flórez por haberme mostrado el programa oficial de celebraciones por la toma de Lima y haberme hecho notar que entre las actividades se llevó a cabo una muestra fotográfica.

15 Expreso mi agradecimiento al coronel Pedro Hormazábal por toda la información que me remitió vía correo electrónico los años 2003 y 2004.

16 El 21 de mayo de 1879.

17 El 20 de octubre de 1879. 
Con respecto a la autoría de las fotos atribuidas a Spencer, la historiadora chilena Alejandra Vega Palma ${ }^{18}$ considera que más de un fotógrafo debió haber colaborado en la sociedad Díaz y Spencer por la simultaneidad temporal con que se llevaron a cabo algunos registros. De acuerdo con Vega las fotografías realizadas en Valparaíso durante 1879, mientras se desarrollaban otros episodios bélicos en Bolivia y Perú, le hacen pensar en la intervención de otro fotógrafo con asiento en las zonas de disputa por el salitre. En todo caso, concluye Vega, Díaz y Spencer aparecen como los comercializadores finales de todas esas vistas. ${ }^{19}$

¿Era Spencer el único que gozaba del privilegio de acompañar a las tropas chilenas durante la guerra? Para Vega Palma todo indica que sí, aunque, como veremos en el caso del estudio Rodrigo (en Tacna), las casas fotográficas establecidas en las ciudades involucradas en la contienda, como Iquique, Tacna y Arica, continuaron operando ${ }^{20}$ al evaluar las posibilidades comerciales de fotografiar a un ejército de ocupación interesado en conservar imágenes suyas en los territorios recién conquistados.

La sociedad Díaz y Spencer documentó inicialmente la guerra con las vistas de todos los buques que hicieron la campaña naval y después con las fotografías tomadas a los oficiales y unidades militares. Sus imágenes tenían dos destinos: el primero era servir como base para los dibujos, grabados y caricaturas de los diarios chilenos de la época, como El Mercurio de Valparaíso y El Nuevo Ferrocarril. El segundo destino era que las familias de cierta posición social tuvieran cómo seguir las acciones y batallas mediante álbumes de fotos de los mandos de batallones, unidades y regimientos.

Tampoco se debe olvidar que los oficiales y suboficiales chilenos, antes de partir de sus ciudades natales como Talca, Concepción, Valparaíso, Santiago, Copiapó, entre otras, se fotografiaban en uniforme militar para dejar el respectivo recuerdo a sus madres, esposas, hermanas, hermanos, amigas o novias. No obstante, estas fueron imágenes tomadas por los fotógrafos que residían en aquellos lugares.

También fue costumbre que, conforme avanzaban las operaciones militares, tanto los oficiales como las tropas se retrataban con motivos de ascensos y condecoraciones. Por otro lado, recordemos que para 1879 se tenía claro el uso que dio Fenton a la fotografía en la Guerra de Crimea y que lo mismo

18 Programa de doctorado de la Universidad Católica de Chile.

19 VEGA PALMA, Alejandra. Algunas preguntas acerca del corpus de fotografías de la Guerra del Pacífico de su ponencia presentada al Congreso Lasa 2004, p. 2.

20 Ibídem, p. 3. 
hizo Gardner en la Guerra de Secesión norteamericana. Además, hay que señalar que el enfrentamiento de Chile contra Perú y Bolivia no fue el primer conflicto fotografiado en Sudamérica: en 1866 la compañía Bate, de Montevideo, registró la etapa más sangrienta de la guerra del Paraguay. ${ }^{21} \mathrm{Y}$, de la misma manera, Courret registró las defensas y baterías peruanas durante el asedio español al Callao que culminarían en el combate del 2 de mayo de $1866 .^{22}$ ¿A qué viene esta síntesis de la fotografía de guerra? A explicar que en el siglo XIX se entendía que el fotógrafo era un comerciante que trabajaba para el ejército al que acompañaba y que su obligación era producir las imágenes que más le convenían a su cliente. La idea de la supuesta objetividad periodística es un tema que recién se empezaría a debatir muy entrado el siglo XX.

Al parecer solo Spencer asistió a los frentes de batalla, por lo que recibió una condecoración otorgada por el gobierno de Chile. En 1884 la sociedad se disolvió pero Spencer continuó haciendo trabajos para el Estado chileno. De aquella época son sus imágenes de los inválidos de la guerra: estas fueron tomadas para tramitar pensiones ante la
Comisión de Sanidad del ejército chileno, donde se confeccionó un álbum en el que, al lado de cada foto aparecía el nombre, antecedentes, tipo de amputación y lugar, entre otros datos. Algunas de estas fotografías fueron tomadas de acuerdo con el tipo de ornamentos que se observan en las fotos en el estudio de Spencer y otras en el de Garreaud, en Santiago, posiblemente a partir de 1885, ya que algunos veteranos lucen medallas otorgadas en 1884.

Spencer se convirtió en fotógrafo oficial de la Presidencia de Chile, retratando al presidente Errazuriz Echaurren y a sus ministros, y acompañándolos en giras dentro de aquel país.

\section{Imágenes de la ocupación (1881-1884)}

De acuerdo con el coronel chileno Pedro Hormazábal, durante la ocupación de Lima (1881 a 1883) las tropas chilenas se retrataron en el estudio de Rafael Castillo y en el de los hermanos Courret. En el Callao algunas tropas lo hicieron en el estudio Maison y Cía., ${ }^{23}$ y en Tacna en la Casa Rodrigo, el más importante de aquella ciudad, con sucursales en Arica e Iquique.

21 Guerra del Paraguay o de la Triple Alianza, que enfrentó a Paraguay contra los aliados Brasil, Argentina y Uruguay (1865-1876).

22 CUARTEROlO, Miguel Ángel. Soldados de la memoria. Buenos Aires: Planeta, 2000.

23 Posiblemente se refiere al establecimiento Fotografía de Mason y Cía, al que el libro Documentos para la historia de la fotografía peruana (Lima: Fundación Telefónica/Museo de Arte de Lima, 2001) da por activo en el Callao recién en 1885. 
Para Hormazábal el establecimiento más importante de aquella época fue el de Courret. Desde los primeros días de la toma de Lima hasta $1884^{24}$ se fotografiaron allí cerca de 300 oficiales y 100 soldados chilenos. ¿Por qué Courret pudo fotografiar sin ser molestado durante aquel periodo? Si bien es cierto que se trataba de un fotógrafo de gran prestigio en el Perú, Eugenio Courret era un ciudadano europeo y, por lo tanto, neutral, que también tuvo una sucursal en Valparaíso, donde su trabajo se hizo conocido. Las importantes relaciones económicas que habría podido llevar a cabo en el principal puerto de Chile podrían ser una razón adicional que explique por qué no tuvo inconvenientes con las tropas chilenas en Lima. ${ }^{25}$

Ampliemos un poco más la historia del estudio Courret en Chile. En agosto de 1868, los hermanos Courret y el también fotógrafo Carlos Luis Rowsell se declararon vecinos en Valparaíso, formando una sociedad para sacar retratos fotográficos por un plazo de tres años. En 1869, Aquiles Courret contrajo un préstamo de nueve mil pesos por dos años con Agustín Edwards, en Valparaíso, para continuar con su giro. Dio en hipoteca su casa en el puerto. Continuó en Valparaíso un año después. ${ }^{26}$ Pero, al parecer, el negocio no prosperó como esperaban los hermanos Courret, ya que para 1871 su tienda ubicada en la calle Cruz de Reyes de Valparaíso era conocida exclusivamente como la Fotografía de Roswell. ${ }^{27}$

En Tacna destacó el retratista Carlos Rodrigo, propietario de la Casa Rodrigo, quien con su taller matriz en Tacna y sucursales en Arica y Antofagasta, logró captar en imágenes a los principales jefes del Ejército peruano-boliviano y luego, a partir de mayo de $1880,{ }^{28}$ a muchos soldados chilenos.

Respecto a la historia de la Casa Fotográfica Rodrigo se puede citar a Hugo Rodolfo Martines, quien transcribió el relato de Armando Holley, hijo del general chileno Luis Adolfo Holley, veterano de la Guerra del Pacífico, en cartas enviadas desde Tacna en 1912 al historiador militar Nicanor Molinaire:

La fotografía de que he hablado data de sesenta años atrás y en cuanto ya no se trabaja en ella por haber muerto su dueño la viuda vende las reproducciones, de lo que tiene, a quien las solicita... Como lo dije en mi anterior, hay planchas de

24 Año en que se retiran las tropas chilenas del Perú.

25 El estudio Castillo tuvo que cerrar en 1882. Recién en 1884 se vuelve a encontrar publicidad suya en la revista El Canal, de Panamá (Fuente: Biblioteca Nacional del Perú).

26 RODRÍGUEZ VILlEgAS, Hernán. Fotógrafos en Chile durante el Siglo XIX. Santiago: Centro Nacional del Patrimonio Fotográfico, 2001, p. 88.

27 Ibídem, pp. 153-154.

28 El 26 de mayo de 1880 el ejército peruano-boliviano fue derrotado en la batalla de Tacna. 
casi todos los militares chilenos, peruanos y bolivianos que actuaron en las campañas de Tacna y Arica; vistas curiosas de esa y otras épocas, etc... hay planchas que se han deteriorado con el tiempo y hay personajes cuyas planchas habría que buscar para sacar reproducciones de ellas, pues no hay muestras en papel... por el momento existen las de Camacho, Cáceres, Valenzuela (chileno del 80), Morales Bermúdez, Justo Arias Araguez (Arica), José María Pérez (boliviano, General Daza, Teniente E. Stange, muerto en Pacía, chileno, Gral. Daza y toda su escolta, Comandante José F. Vargas (Dragones), Inclán, Murgía de los colorados, Coronel Amengual; toda la oficialidad y jefes del Esmeralda; Daza; soldados chilenos, peruanos y bolivianos; grupos de los Jefes de los buques españoles que mandaban la guerra del 66; jefe del batallón Victoria (peruano); Adolfo Ugarte (Arica); vistas curiosísimas de los funerales del General Castilla en Arica; Com. Holley, Máximo Lira, cantineras chilenas, etc.

En una carta anterior, siempre citando a Ramírez, se hace mención a un comentario que le envía Holley a Molinaire sobre otro hallazgo:

Rebuscando en el sinnúmero de curiosidades que guarda esta fotografía, he encontrado el retrato del actual Presidente de Argentina, Sr. Sáenz Peña, que no he podido dejar de comprarlo, recordándolo a Ud. Por sus obras, para enviárselo si le es de alguna utilidad para el futuro... el hoy general peruano, está en traje de la época usado por el ejército del Perú y creo que muy pocos pueden contar con tan bello ejemplar histórico. ${ }^{29}$

Un caso desafortunado fue el de nuestro compatriota Juan de la Cruz $\mathrm{Pa}$ lomino, quien llegó a tener una vasta producción en Chile. Su establecimiento conocido como Fotografía Peruana tuvo mucha aceptación en Concepción, habiendo numerosos retratos suyos fechados en 1878. Sin embargo, la Guerra del Pacífico lo afectó en su actividad profesional, ya que no se volvió a encontrar obra suya posterior a 1880. Al pasar los años, y conforme iban cerrando las heridas de la guerra, se le volvió a citar como fotógrafo establecido en la ciudad de Talca, en la Guía Jeneral de Chile por Aníbal Labarca en 1898 y en el Anuario Prado Martínez de 1903. ${ }^{30}$

\section{Imágenes y memoria}

En los diarios de algunos combatientes chilenos existen anotaciones muy interesantes referentes al uso de la fotografía durante la Guerra del Pacífico. Así, el doctor Guillermo Castro Espinosa, ${ }^{31}$ en

29 RAMÍREZ, Hugo Rodolfo. "Notas sobre el origen de la fotografía en Chile". Revista Universitaria 7. Santiago, 1982, pp. 62-75.

30 Ibídem, pp. 142 y 143.

31 Cirujano primero del ejército chileno de operaciones del norte. 
su diario personal, ${ }^{32}$ señala el viernes 17 de diciembre de 1880: "Dublé A. saca una vista del convoy". 33 Castro Espinosa y Dublé ${ }^{34}$ se encontraban embarcados en el transporte Amazonas y en aquellos momentos navegaban junto a 22 barcos que transportaban a los casi treinta mil hombres que atacarían la Ciudad de los Reyes en enero de 1881. Posteriormente, ya durante la ocupación de Lima, el 13 de junio de 1881 Espinosa acudió al estudio Courret: "Me mandé sacar una docena de retratos donde Courret"35, escribió.

Por su parte, y con muchos menos recursos que un oficial cirujano, el soldado Abraham Quiroz envió una carta a su padre el 26 de abril de 1881 solicitándole cinco pesos: "Tengo que retratarme y mandarle mi retrato y comprar otras cosas más". ${ }^{36}$ Lamentablemente Quiroz enfermó de terciana y el 13 de julio de 1881 volvió a escribir a su padre desde Lima para agradecerle por el dinero que había enviado, pero indicándole que todavía no se sacaba el re- trato por estar enfermo: "Ahora ya estoy mejor y lo haré y se lo mandaré a usted". 37 Finalmente, y ya en Huancayo, enfrentándose a las tropas de Cáceres, le escribió a su padre expresándole su alegría, al haberle llegado sus fotos. ${ }^{38}$

Un caso muy especial por su calidad de británico y combatiente en la Marina de Guerra chilena es el del suboficial Edwin John Penton, que sirvió a bordo del acorazado Almirante Cochrane desde 1878 a $1882 .{ }^{39}$ El marinero victoriano escribió un diario ${ }^{40}$ donde narraba prácticamente todas las acciones navales de la Guerra del Pacífico, entre ellas la captura del Huáscar $\mathrm{y}$ algunas acciones terrestres en las que apoyó su barco, como en la toma de Arica y las batallas por Lima. Entre sus múltiples anotaciones dejó algunas sobre la captura del Huáscar que llaman la atención. Finalizado el combate de Angamos, Penton fue enviado al capturado blindado peruano para evaluar los daños. Al subir a cubierta describió un escenario de horror sobre la cubierta de la nave:

32 CASTRO ESPINOSA, Guillermo. Guerra del Pacífico: Diario de campaña 1880-1881, 1986.

33 Ibídem, p. 57.

34 Diego Dublé Almeida es un oficial de artillería chileno que participa en las batallas de Pisagua, San Francisco, Tacna, la campaña de Lima y la expedición a Arequipa.

35 CASTRO ESPINOSA, Guillermo. Op. cit., p. 81.

36 QUIROZ, Abraham e Hipólito GUTIÉRREZ. Dos soldados en la Guerra del Pacífico. Santiago: Editorial Francisco de Aguirre, 1976, p. 89.

37 Ibídem, p. 91.

38 Ibídem, p. 95.

39 Era común que se enrolaran europeos en las naves peruanas y chilenas. Incluso encontramos en la tripulación del Huáscar la presencia de británicos, un francés y un danés.

40 PENTON, Edwin John. Diary of a victorian seamen. Surrey: Roger D. Clark, 2001. 
The first thing that met our eyes were heaps of debris, splinters of wood, iron, broken shell and numerous articles all intermixed with the bodies of the dead, dying and wounded, fearfull to behold, some headless, others without arms, others without legs, and some only with trunks, some with their clothes burnt off, others with the buttons of their cloths charred and burnt off by the bursting of shell, This awfull spectacle was equally as bad below as on the desk. ${ }^{41}$

Luego de su captura por la Marina de Guerra chilena el blindado peruano fue fotografiado en Antofagasta y Valparaíso. Era indispensable documentar el nuevo estado de las cosas lo más pronto posible. El Huáscar había impedido por seis meses cualquier intento de invasión al Perú y a partir del 8 de octubre de 1879 la guerra daría un giro definitivo a favor de Chile. Al retratar al blindado este resultaba doblemente capturado: dominado en su materialidad y, a la vez, retenido artificialmente por la imagen.

La fotografía más famosa del Huáscar, aunque todavía muy poco vista en el Perú, es la que tomó Spencer en Valparaíso. En ella se observan los daños sufridos por el blindado en Angamos y, si tomamos en cuenta que el Huás- car arribó el 20 de octubre de 1879 y el 22 se le comenzó a reparar, se puede presumir que la fotografía fue tomada al poco tiempo de llegar la nave al puerto. ${ }^{42}$

Sin embargo, la fotografía no nos transmite ni recrea la sensación de horror que se produce al leer el diario de Penton. No se escuchan los gritos de los heridos, tampoco se siente el olor a carne quemada ni el humo de los incendios. No hay una descripción cabal del horror pero sí un nivel de sugerencia. La imagen solamente buscaba demostrar a la opinión pública que el gran adversario había sido vencido. No pretendía inquietar mostrando escenas de una lucha excesivamente sangrienta. Como señala Gonzalo Leiva respecto a las fotografías chilenas de la Guerra del Pacífico, "tienen demasiado marcadas el signo de ser la historia oficial del conflicto". ${ }^{43}$

\section{Imágenes y la resistencia en los Andes}

¿Documentaron los fotógrafos chilenos la campaña de La Breña? Para el investigador Patricio Greve ${ }^{44}$ solo llegaron hasta Lima, ya que la motivación principal de Spencer eran las fotos en cam-

\footnotetext{
41 Ibídem, p. 42.

42 Ibídem, p. 45.

43 LEIVA QUIJADA, Gonzalo. "Representación fotográfica en la Guerra del Pacífico: Una visión chilena". Ponencia en el Congreso de la Sociedad Iberoamericana de Historia de la Fotografía, p. 119.

44 Investigador chileno de la Guerra del Pacífico.
} 
paña. Para la época, continúa Greve, ocupada Lima se pensaba en Chile que la guerra ya estaba ganada. Las últimas fotos de la guerra tomada por la sociedad son las del recibimiento a las tropas chilenas y los arcos del triunfo levantados en su honor a su regreso a Valparaíso. ${ }^{45}$ Sin embargo, el coronel Hormazábal señala que otros establecimientos como Leblanc también concurrieron a los escenarios bélicos. La importancia de Díaz y Spencer radica en sus fotos del Huáscar capturado y de la ocupación chilena de Antofagasta, Iquique, Pisagua, Arica, Tacna y Lima.

Por otra parte, no se puede descartar la existencia de imágenes de tropas peruanas o chilenas durante los enfrentamientos de 1881 a $1884 .{ }^{46}$ La fotografía y los estudios fotográficos eran activos en la sierra del Perú en la segunda mitad del siglo XIX. Incluso, y aunque es un periodo posterior a la Guerra del Pacífico, revisando el diario del viajero francés Oliver Ordinaire ${ }^{47}$ se encuentra que llegó a la ciudad de Tarma en 1885 y se une a un grupo de soldados y rabonas $^{48}$ del ejército de Cáceres:
En el claustro del antiguo convento de Tarma trasformado en caserna, las rabonas pasaban una parte del día sentadas en el suelo, con la cabeza entre las manos como las momias que se encuentran ordenadas en ciertas grutas de los Andes. Mientras que descansaban así de sus últimas etapas, apunté hacia ellas mi cámara fotográfica, y no pude hacer menos que fotografiar en la misma ocasión una de las seis piezas de montaña fundidas en Arequipa para el general Cáceres. ${ }^{49}$

El propio Cáceres tuvo una dramática anécdota relacionada con la fotografía en junio de 1884, al confrontar a un destacamento chileno que había llegado a Huancayo buscándolo para que reconociera al gobierno de Iglesias. ${ }^{50} \mathrm{El}$ jefe de la unidad militar chilena, coronel José Antonio Gutiérrez, apodado "El Araucano", le escribió una carta al jefe de la resistencia peruana:

\begin{abstract}
Tenía orden de atacarme en caso de no aceptar la propuesta del Dr. Amstrong; ${ }^{51}$ pero no lo haría sin participarme antes su resolución, pues no atacaría por sorpresa a un jefe que defiende honradamente a su patria. Le contesté que me
\end{abstract}

45 En 1881. Las tropas de ocupación chilenas permanecieron en el Perú hasta 1884.

46 Periodo conocido también como la Campaña de La Breña, en la que se desarrolló la resistencia contra el invasor, especialmente en la sierra central del Perú.

47 ORDINAIRE, Olivier. Del Pacífico al Atlántico y otros escritos. Iquitos: IFEA, 1988.

48 Nombre con el que se conoce a las mujeres que acompañaban a los soldados del ejército peruano durante las guerras del siglo XIX.

49 pp. 59 y 60.

50 General peruano que firmó la rendición peruana en el Tratado de Ancón, por el cual concluyó la Guerra del Pacífico.

51 Secretario del contralmirante chileno Patricio Lynch. 
agradaba tener como adversario a un jefe caballeroso y que, si llegado el caso, podríamos batirnos con fuerzas iguales en campo abierto. Antes de marcharse me escribió nuevamente y como prueba de su simpatía y recuerdo me envió su retrato con la sencilla y significativa dedicatoria: "A mi estimado enemigo". Le respondí agradeciéndole su gentileza y, como recíproco testimonio de mi simpatía, le remití también el mío. ${ }^{52}$

De esta manera, y casi al terminar la Guerra del Pacífico, la fotografía podía ayudar a un primer honorable entendimiento entre los hasta entonces encarnizados enemigos chilenos y peruanos.

\section{Bibliografía}

AHUMADA MORENO, Pascual. Recopilación completa de todos los documentos oficiales, correspondencias $i$ demás publicaciones referentes a la guerra. Tomo IV. Valparaíso, 1887.

CÁCERES, Andrés A. Memorias de la guerra del 79. Sus campañas. Lima: Milla Batres. La campaña constitucional, 1973.

CASTRO ESPINOSA, Guillermo. Guerra del Pacífico: Diario de campaña 1880-1881.
CUARTEROLO, Miguel Ángel. Soldados de la memoria. Buenos Aires: Planeta, 2000.

LEIVA QUIJADA, Gonzalo. "Representación fotográfica en la Guerra del Pacífico: Una visión chilena". Ponencia en el Congreso de la Sociedad Iberoamericana de Historia de la Fotografía.

ORDINAIRE, Olivier. Del Pacífico al Atlántico y otros escritos. Iquitos: IFEA, 1988.

PENTON, Edwin John. Diary of a victorian seamen. Surrey: Roger D. Clark, 2001.

QUIROZ, Abraham e Hipólito GUTIÉRREZ. Dos soldados en la Guerra del Pacífico. Santiago: Editorial Francisco de Aguirre, 1976.

RAMÍREZ, Hugo Rodolfo. "Notas sobre el origen de la fotografía en Chile". Revista Universitaria 7. Santiago, 1982.

RODRÍGUEZ VILLEGAS, Hernán. Fotógrafos en Chile durante el siglo XIX. Santiago: Centro Nacional del Patrimonio Fotográfico, 2001.

VEGA PALMA, Alejandra. Algunas preguntas acerca del corpus de fotografías de la guerra del Pacífico de su ponencia presentada al Congreso Lasa 2004.

52 CÁCERES, Andrés A. Memorias: La guerra del 79 y sus campañas. Lima: Milla Batres. La campaña constitucional, p. 39. 